concerns. Such knowledge I call Ecological Philosophy. The creation of this first Chair of Ecological Philosophy is an act of courage and wisdom; perhaps in the future it will come to be considered an act of far-sighted prudence.

Poland needs help and the environment needs help. Poland has been in the forefront for political change in recent years, experimenting with models that others, expecially those in Eastern Europe, have followed. Now Poland embarks on yet another experiment - this time in the sphere of education. Would it be too much to expect that enlightened and concerned people and foundations will help Poland in this new venture, which is as bold as it is innovative, and of potential importance to us all?

HENRYK K. SKOLIMOWSKI, Professor
University of Michigan
College of Engineering Program in Humanities
550 East University Avenue
Ann Arbor
Michigan $48109-1092$
USA.

\title{
The WHO Global Programme on AIDS
}

The World Health Organization (WHO) Global Programme on AIDS (GPA) coordinates and directs the global fight against AIDS. WHO is responsible for the implementation of the three objectives of the Global AIDS Strategy, namely: (1) to prevent HIV infection, (2) to reduce the personal and social impact of HIV infection, and (3) to unify national and international health efforts. WHO's Global AIDS Strategy has received the support of practically every country in the world, of the World Health Assembly, of the United Nations General Assembly, and of the World Summit of Ministers of Health on Programmes for AIDS Prevention.

Global activities of GPA include organizing and cosponsoring technical and scientific meetings and consultations on research and policy issues. In 1990, activities of GPA required a total of US $\$ 90.7$ millions. About 50 per cent of this amount was obligated to support countrybased programmes.

In order to meet the challenge of AIDS in the coming decades, especially as it affects the 'developing world', the four priority aspects of WHO policy are: (1) strengthening collaboration with national AIDS control programmes; (2) focus on, and acceleration of, concomitant research and development activities; (3) preventing complacency and denial which threaten to undermine current actions and seriously to hamper future efforts; and (4) reinforcing effectiveness in the area of human rights.

S. Holck, Policy Coordinator
World Health Organization
20 Avenue Appia
1211 Geneva 27
Switzerland.
World Health Organization 1211 Geneva 27 Switzerland.

\section{OECD Countries Begin Cooperative Safety-testing on Chemicals}

Member countries of the Organization for Economic Cooperation and Development (OECD) have agreed to share out the work of testing a first group of 42 industrial chemicals that are produced in high volume. The decision, taken at a meeting of industry and government experts during 12-15 November 1990, follows an earlier decision, taken in April 1990, to collect information, evaluate it, and where necessary carry out, on a cooperative basis, new testing on the High Production Volume (HPV) industrial chemicals for which only limited environmental and safety data are available. Agreement was reached on future work as follows:

- for five chemicals, the data available, mainly from industry files, was judged sufficient to allow an initial assessment of their hazard potential;

- for 37 other chemicals, specific testing will be undertaken in 1991, in most cases by industry. This will include extensive tests for health-related parameters such as genotoxic and reproductive effects as well as any environmental risks.

This cooperative OECD work relies heavily on the voluntary cooperation of chemical companies which are providing privately-held data, and are also undertaking the specific testing required. The long-term objective of the programme is to ensure that there is an evaluation of the potential hazards of each of the chemicals produced in high volume (HPV chemicals). Based on such an eva- luation, national and, as appropriate, international action to reduce any risks stemming from use of these chemicals will be undertaken when necessary.

The programme is expected to address altogether some 1,500 HPV chemicals which have been identified by Member countries as being produced in quantities exceeding 1,000 tonnes per year world-wide. Work on testing the next group of about 100 priority HPV chemicals will begin in mid-1991. The OECD Business and Industry Advisory Committee (BIAC), and national chemical industry federations, have been of great assistance in promoting the collection of pertinent data.

The data compiled in this OECD Programme will be made available world-wide through the United Nations International Register of Potentially Toxic Chemicals and International Programme on Chemical Safety. Quite apart from the benefits accruing to public health and the environment, the cooperative safety-testing agreement will substantially alleviate the financial costs involved, and will also take account of animal welfare, as countries will share the work and accept each other's testing results.

Organization for ECONOMIC COOPERATION AND DEVELOPMENT

2 rue André-Pascal

75775 Paris Cedex 16

France. 